\title{
Mating of Captive Thirteen-Lined Ground Squirrels and the Annual Timing of Estrus
}

\author{
I. Theodore Landau* and Warren G. Holmes ${ }^{\dagger}$ \\ *Psychology Department, Oakland University, Rochester, Michigan 48309, and \\ $\ddagger$ Psychology Department, University of Michigan, \\ Ann Arbor, Michigan 48109
}

\begin{abstract}
Thirteen-lined ground squirrels (Spermophilus tridecemlineatus) have a single annual mating season in Michigan, beginning shortly after their spring emergence from hibernation. Captive females were studied during a 3-year period to determine relations among time of removal from the coldroom, vaginal estrus, and mating behavior. Following a 7 -month period females spent in a coldroom, vaginal lavages were taken daily to monitor changes in estrous condition. Females removed from the coldroom about when free-living animals emerge from hibernation were in vaginal estrus within $24-48 \mathrm{hr}$ and had an initial period of persistent estrus (ca. 3 weeks), followed by briefer $(<1$ week) and more sporadic estrous periods. Females left in the coldroom 3 weeks longer than normal had significantly briefer initial periods of vaginal estrus after being removed from the coldroom. Similarly, virgin Yearlings and virgin 2-Year-Olds had significantly briefer initial periods of estrus than nonvirgin Adults ( $\geqslant 2$ years old). In 1985, eight of eight females paired with males mated within the first week after removal from the coldroom and subsequently produced litters. Mated females remained in vaginal diestrus from within a few days of mating until after parturition. In contrast, unmated females remained in prolonged vaginal estrus during this period. Females first paired with males 3 weeks after being taken from the coldroom failed to mate. In 1986, five of six females first paired with males 2 weeks after being removed from the coldroom similarly failed to mate. However, five of six females did mate that were removed from the coldroom 10 days after those in the previously described group and paired with a male 4 days after removal. This first report of reliable mating behavior in captive thirteen-lined ground squirrels should facilitate subsequent analysis of reproductive patterns in this species. (c) 1988 Academic Press, Inc.
\end{abstract}

North American ground squirrels (genus Spermophilus) inhabit seasonally variable environments in which ecological conditions favorable for breeding and rearing young are restricted to a few months each year. Accordingly, these species have evolved annual activity cycles that include a 5-8 month hibernation period, followed by an active period which begins with mating in the spring. For female ground squirrels, reproductive 
timing is critical because (1) they rear their litter alone, (2) lactation induces the maximum rate of daily energy expenditure of any age-sex class (Kenagy, 1986), and (3) their offspring need several months to grow and deposit adequate body-fat stores to survive a hibernation period when food is unavailable (Davis, 1976). Thus, females typically mate shortly after vernal emergence and produce only one litter annually (references in Murie and Michener, 1984). Young born to late-breeding females have reduced over-winter survival rates (Armitage, Downhower, and Svendsen, 1976). As a result, one might expect females that do not mate soon after emergence to enter a nonbreeding state to protect against late litters that would have low survival probabilities. However, field observations cannot confirm this expected anestrus because, in years when the timing and form of spring weather conditions are normal, females typically mate within 1 week of emergence (Michener, 1985; Murie and Harris, 1982; Sherman and Morton, 1984; Slade and Blaph, 1974).

Thirteen-lined ground squirrels ( $S$. tridecemlineatus) are obligate hibernators found over a geographic range that stretches from Texas in the United States to south-central Canada (Hall, 1981). The timing of emergence and mating varies geographically, with emergence generally occurring later in the spring for animals in the more northern latitudes (Joy, 1984). Thus, in northern populations, males emerge in April and females about 2 weeks later, by which time males are reproductively active (Moore, Simmons, Wells, Zalesky, and Nelson, 1934; Wells, 1935). This pattern of emergence of adult males before adult females is characteristic of nearly all ground squirrel species (Michener, 1984). In Michigan, female $S$. tridecemlineatus copulate within 1 week of emergence, mating usually within several hours of when they first become behaviorally receptive, and then quickly becoming unreceptive (as rapidly as $1 \mathrm{hr}$ after mating) until the next spring. During this period, females often mate with more than one male (Schwagmeyer, 1984; Schwagmeyer and Brown, 1983).

Studies of the relation between thirteen-lined ground squirrels' reproductive behavior and physiology have been hindered by the difficulty of getting animals to breed reliably under standard laboratory conditions (e.g., Johnson and Wade, 1931). Captive matings have been reported using environments that simulated some aspects of the species' natural habitat. Bridgwater (1966), using $2.4 \times 3.6-\mathrm{m}$ indoor enclosures with nestboxes buried under soil, obtained four instances of mating with 28 females. Barr and Musacchia (1968) had limited success using $1.2 \times 2.1$ $\mathrm{m}$ outdoor pens. Thus, an initial focus of the present study was to breed $S$. tridecemlineatus under standard laboratory conditions. Having accomplished this, we (1) determined the temporal pattern of vaginal estrus in both unmated and mated females, (2) examined the relation between vaginal and behavioral estrus, and (3) determined how females reproduction 
was affected by both the calendar date they were removed from the coldroom and when they were paired with males.

\section{METHODS}

\section{Experiment}

Females used in the 1984 experiment were 11 adults ( $\geqslant 2$ years old) trapped (when pregnant) near Ann Arbor, Michigan $\left(42^{\circ} \mathrm{N}\right.$ latitude) during 20-24 May 1983. The offspring of these females were also used. They were born ( 24 May-7 June) in the laboratory $\left(20^{\circ} \mathrm{C}\right.$, natural light and photoperiod) and remained with their dams and littermates until weaning occurred naturally (ca. 28 days of age). Subsequently, all animals were given food (Purina mouse breeder chow, ca. $5 \mathrm{~g}$ ) and water (ad libitum) daily, On 22 September 1983, dams and their juvenile daughters weighed $164.5 \pm 8.0 \mathrm{~g}$ (mean $\pm \mathrm{SEM}$ ) and $112.8 \pm 7.2 \mathrm{~g}$, respectively, both of which matched ( $\pm 12 \mathrm{~g}$ ) the weights of free-living ground squirrels about to enter hibernation in the Michigan population where our animals originated (Schwagmeyer, personal communication).

Females were caged individually in a coldroom (ca. $5^{\circ} \mathrm{C}$, constant darkness, no food or water) where they remained until 24 April 1984, when four adults and five yearlings (juveniles born the previous summer) were taken from the coldroom. Because free-living females in Michigan typically emerge from hibernation during the second or third week of April (Schwagmeyer, 1979), animals removed from the cold on 24 April were labeled Normal Adults (with respect to emergence date) and Normal Yearlings, respectively. On 15 May 1984, seven more adults and five yearlings were removed from the coldroom and labeled Delayed Adults and Delayed Yearlings, respectively. Upon removal, all animals were housed individually in plastic cages $(38 \times 33 \times 18 \mathrm{~cm})$ under the same laboratory conditions they experienced the previous summer (e.g., natural photoperiod).

Vaginal lavages were taken (see Holmes and Landau, 1986) from females within $3 \mathrm{hr}$ of removal from the coldroom (Day 1, Week 1), followed by daily collections (six per week) for 16 weeks beginning 1 May. Lavages were immediately inspected under a microscope $(100 \times$ magnification) and classified according to standard criteria (Turner and Bagnara, 1976). Briefly, estrus $(E)=$ a clear predominance of cornified cells; diestrus (D) = a majority of leucocytes; metestrus $(\mathrm{M})=$ approximately equal proportions of cornified cells and leucocytes; proestrus $(P)=$ a majority of nucleated cells. Lavages were also described as borderline between two states (e.g., P/E). Patterns that could not be clearly classified into any of these categories were noted and described (e.g., see Fadem and Rayve, 1985). Intra- and interrater $(N=4)$ reliability in the classification of 30 randomly chosen slides was $>95 \%$. Hereafter, "estrus," unless 
stated otherwise, refers to vaginal estrus as determined from vaginal lavages.

For the statistical analyses, an estrous period was defined as a series of consecutive days that an animal was rated as $\mathrm{E}, \mathrm{E} / \mathrm{P}$, or $\mathrm{E} / \mathrm{M}$. The criterion for anestrus was 21 consecutive days without being rated as $\mathrm{E}$. The scores of adults and yearlings on (1) duration of first estrous period (subsequent to removal from the coldroom), and (2) duration of longest estrous period were compared with a $2 \times 2$ (Age $\times$ Time of Removal) analysis of variance and Student's $t$ test. Means \pm SEM are reported. Adults' and yearlings' scores were analyzed separately because adults had reproduced previously, whereas yearlings had not.

\section{Experiment}

Females used in 1984 were prepared for the 1985 experiment by placing them in the coldroom (the same conditions as those in the previous year) on 5 September 1984, when adults weighed $153.5 \pm 9.1 \mathrm{~g}$ and yearlings weighed $147.8 \pm 8.5 \mathrm{~g}$. On 29 April 1985, four Adults and four 2-YearOlds (yearlings the previous summer) were taken from the coldroom and housed individually under the same conditions as the previous summer.

To examine the relation between vaginal lavages and mating behavior, an additional four Adults and four 2-Year-Olds, removed from the cold on 29 April, were placed individually in one of two sizes of Masonite mating enclosures (either $81 \times 81 \times 61$ or $71 \times 51 \times 46 \mathrm{~cm}$ ), each of which contained two $25 \times 15 \times 10$-cm plywood nestboxes. Three days later, eight males were placed in the mating enclosures, one male per enclosure. Each male was initially restricted to its individual plastic cage, but was released $24 \mathrm{hr}$ later, permitting direct interactions with the female. Males were trapped (20-22 April) near Ann Arbor, Michigan, and appeared reproductively active when placed in the enclosure: They all had enlarged, descended testes in darkly pigmented scrota, mimicking free-living males during the breeding season (Schwagmeyer, 1979). Two of eight males were observed mating with free-living females on the day they were trapped.

Vaginal lavages were collected daily from all females, starting on the day of removal from the coldroom (29 April) and continuing until 20 July 1985. Collections were reduced to 6 days per week starting the seventh week. For females paired with males, sperm in the vaginal lavage was used as an initial criterion that mating had occurred during the previous $24 \mathrm{hr}$. Females and males were returned to separate plastic cages after evidence of mating was detected. Females and males not showing evidence of mating were returned to individual cages 11 days after initially being paired. However, all females paired with a male became pregnant and are henceforth referred to as Mated Females. The remaining females are referred to as Unmated Females. Offspring born to Mated Females initially 
remained in the cage with their littermates and dam until offspring were housed separately at 37-38 days of age.

Last, 22 days after having been taken from the coldroom (15 May), two Adult and two 2-Year-Old females that had not previously been paired with males were placed individually in mating enclosures. A male was placed in each mating enclosure (see above) and 7 days later all animals were returned to individual plastic cages. Females in this group were contrasted with those females paired with males previously. For these contrasts, females taken from the coldroom at the "normal" time (i.e., coincident with emergence of free-living animals) and "immediately" paired with males were referred to as the Normal-Immediate group (NorImm). Females paired with males 22 days after being removed from the coldroom were referred to as the Normal-Delayed group (Nor-Dly).

Statistical analyses of estrous period duration were similar to those described for 1984. Groups were analyzed using an Age $\times$ Mating Condition analysis of variance. Differences in the number of females that became pregnant among the three groups were analyzed by $\chi^{2}$ and/or Fisher's exact probability test. To permit a qualitative inspection of daily records, estrous ratings for all females were graphed as a function of the percentage of animals on each day that were rated as $\mathbf{E}, \mathbf{E} / \mathbf{P}$, or $\mathbf{E} / \mathbf{M}$ through Week 8 after removal from the coldroom.

\section{Experiment}

Unless otherwise noted, all methodological and statistical procedures follow those used in 1985.

Females used in 1985 were prepared for the 1986 experiment by placing them in the coldroom on 27 September 1985. On 25 April 1986, eight adults and three yearlings were taken from the coldroom and housed individually. Vaginal lavages were collected daily from all females until 5 May 1986, and 6 days/week thereafter until 31 July 1986.

Initially, two groups were created: the first included four adults and one yearling. Each of these females was housed in a mating enclosure with a male beginning 4 days after female removal from the coldroom and ending either after evidence of mating (sperm detected in the daily vaginal lavage) or after 10 days. As in 1985 , females were referred to as the Normal-Immediate group (Nor-Imm). The second group of females included four adults and two yearlings that were initially paired with males 14-16 days after female removal from the coldroom. These animals were referred to as the Normal-Delayed group (Nor-Dly).

A third group (four adults and two yearlings) was subsequently created by removing females from the coldroom on 5 May 1986, 10 days after the first two groups were removed, and pairing them with males 4-6 days later. Because removal of these females was "delayed" (compared with the first two groups) though they were still paired with males "im- 
mediately" after removal from the cold, this group was referred to as the Delayed-Immediate group (Dly-Imm).

Males acquired and used in 1986 mating tests were in apparent reproductive condition when paired with females (see 1985 mating tests described above).

During mating tests, randomly selected single pairs were videotaped continuously for $24 \mathrm{hr}$ with a Panasonic AG-6010 VHS video cassette recorder attached to a Panasonic color video camera mounted on a tripod. Eight such recordings were made and were later reviewed for evidence of mating. Overhead fluorescent lights were left on at night during these tests to permit taping.

\section{RESULTS}

\section{Latency, Duration and Pattern of Vaginal Estrus}

For baseline data collected in 1984 and 1985, all animals in all conditions were in estrus within $48 \mathrm{hr}$ of removal from the coldroom (range - 1.0 \pm 0.0 to $1.8 \pm 0.3$ days). The most common pattern was for this initial estrus to persist uninterrupted for 2-5 weeks. Subsequently, females began to show briefer and more sporadic estrous periods ( $1-3$ days long). These continued for another several weeks, ultimately terminating in anestrus. One exception to these generalizations were the Delayed Yearlings in 1984 , which showed a brief initial estrous period $(3.0 \pm 0.3$ days $)$ followed by a second longer period $(18.2 \pm 8.7$ days $)$.

The mean length of the longest estrous period (consecutive days of $\mathrm{E}, \mathrm{E} / \mathrm{P}$, or $\mathrm{E} / \mathrm{M})$ for all 1984 animals $(N=21)$ was $21.0 \pm 5.6$ days. The longest estrus period was significantly briefer for Normal Yearlings than Normal Adults ( $15.4 \pm 1.9$ vs $36.8 \pm 12.3$ days; $P \leqslant 0.05, t$ test). The longest estrous periods of both Delayed Adults and Delayed Yearlings were also significantly briefer than those of Normal Adults $(20.6 \pm 8.9$ and $18.2 \pm 8.7$ vs $36.8 \pm 12.3$ days, respectively; $P \leqslant 0.05$ ). In 1985, there was a similar significant difference between the longest estrous period of Unmated Adults vs Unmated 2-Year-Olds (Yearlings the previous year) $(28.0 \pm 6.9$ vs $11.3 \pm 0.9$ days; $P \leqslant 0.05)$.

\section{Mating and Patterns of Vaginal Estrus}

1985 Experiment. Five (three Adults plus two 2-Year-Olds) of eight females paired with males 3 days after removal from the coldroom had sperm present in the vaginal lavage within $48 \mathrm{hr}$ of direct exposure to males (i.e., Days 4-5 after removal from the coldroom). Sperm were never detected in samples from the remaining three females. Nevertheless, all eight females (Nor-Imm) must have mated during this 48 -hour period because all of them delivered young 27-28 days after access to a male. Presumably, the once daily vaginal lavages (taken between 0930-1130 


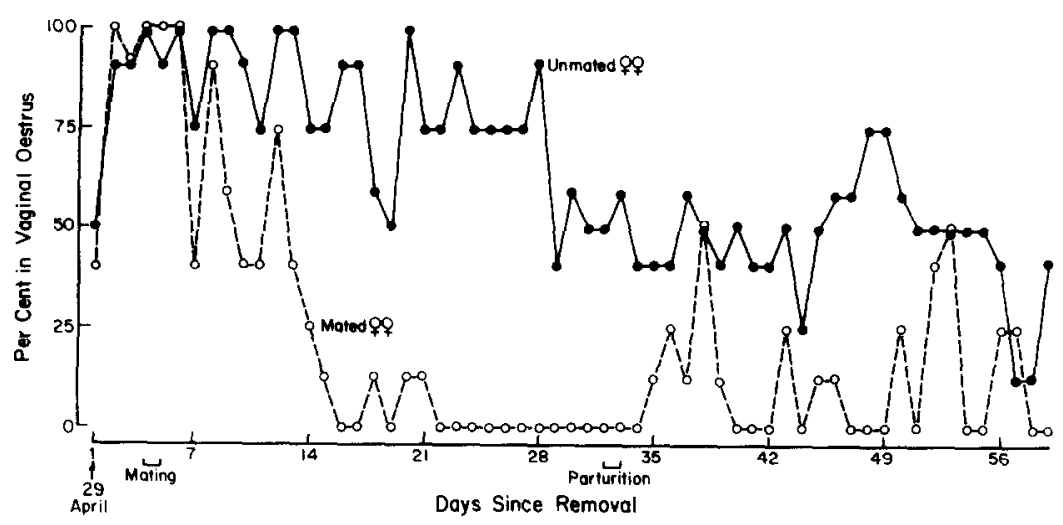

Fig. 1. Percentage of animals in vaginal estrus [Unmated $(N=8)$ vs Mated $(N=8)$ ] for the first 59 days after removal from the coldroom on Day 1 (29 April 1985). Data for Adults and Two-Year-Olds are combined. Mated females were given direct access to males on Day 4, conceptions occurred on Days 4-5, and litters were born on Days 32-33. Vertically adjacent points represent identical values.

hours) were not collected near enough to the time of mating to detect sperm in three females.

Sperm were never detected in the vaginal lavages of four females paired with males beginning 22 days after females were taken from the coldroom (Nor-Dly). Neither did any of these females deliver young nor otherwise show vaginal estrous changes characteristic of pregnancy (see above). Thus, we concluded that none of these females mated ( $\chi^{2}$ for Nor-Imm vs Nor-Dly $=12.04, P<0.001)$, despite the fact that they were in vaginal estrus for at least the initial days of being paired with a male. Throughout this period, all males had darkly pigmented scrota and descended testes, indicative of a potential for reproductive behavior (see Mcthods, 1985 Experiment). The estrous patterns of thesc unmated fcmales paired with males were indistinguishable from those of females never paired with a male. Thus, these four females plus those that were never paired with a male were considered to be a single group $(N=8)$ for statistical purposes and referred to as Unmated Females (see Fig. 1).

Animals that were successfully mated 4-5 days after removal from the coldroom terminated estrus within the next few days (Adults $=7.8$ \pm 2.1 days after mating; 2 -Year-Olds $=8.3 \pm 2.1$ days after mating). These estrous durations for mated animals were also significantly shorter than those of Unmated Adults $(28.0 \pm 6.9$ days $)$. After the postmating termination of estrus, the females remained in a state of relatively constant diestrus until at least after parturition.

After parturition, mated females showed sporadic occurrences of estrus, never more than 2 days long, for the remainder of the sampling time. 
In contrast, four of eight Unmated Females had longer periods of estrus during this time. All Mated Females attained the anestrous criterion by the termination of data recording (50 days after parturition), whereas only three of eight Unmated Females (two 2-Year-Olds and one Adult) similarly attained the anestrous criterion.

1986 Experiment. Two of five Nor-Imm females (40\%) became pregnant and both bore young 27-28 days after being paired with a male. We do not know why only $40 \%(2 / 5)$ of 1986 Nor-Imm females became pregnant while $100 \%(8 / 8)$ of 1985 Nor-Imm females did so. All 1985 and 1986 females were in vaginal estrus during the period that they were paired with males.

Females in the Nor-Dly and Dly-Imm groups were paired with males on the same calendar date, but differed in that Nor-Dly females had been removed from the coldroom 2 weeks prior to the mate pairing, whereas Dly-Imm animals had been removed 4 days prior to the pairing. All females were in vaginal estrus (only cornified cells were present in the vaginal lavage) during at least the first 4 days after being paired with a male. Nevertheless, only one of six Nor-Dly females $(16.7 \%)$ produced young, whereas five of six Dly-Imm females (83.3\%) did so. Again, all litters were born $27-28$ days after initial pairing with a male.

The number of females that produced young differed $\left(P \leqslant 0.001 \chi^{2}\right.$ $=16.37)$ among the three groups. Similarly, the number of females producing young differed $(P \leqslant 0.001$; Fisher test) between the Nor-Dly and Dly-Imm groups (Table 1).

One instance of mating was recorded on videotape. Eight mounts with thrusting were observed, all occurring between 0630 and $0835 \mathrm{hr}$ (near the end of the 24-hr observation period). Typically, a mount was preceded by the male chasing the female for a short duration. Once mounted, the female became relatively immobile for the duration of the mount. During six of the mounts, the male remained on the female between 2-5 sec, whereas two other mounts lasted 21 and $25 \mathrm{sec}$, respectively. Thrusting occurred throughout the duration of the mount. We could not determine whether intromission or ejaculation occurred on a specific mount, but ejaculation occurred during the series of eight mounts because sperm were detected later in the vaginal lavage and the female became pregnant. In nature, females are mounted repeatedly by the same or different males during a receptive period of $1-5 \mathrm{hr}$, and mounts vary in duration from under $10 \mathrm{sec}$ up to $17 \mathrm{~min}$ (Schwagmeyer and Brown, 1983).

\section{DISCUSSION}

Females in the Michigan population where our animals originated typically mate within 1 week of vernal emergence and become nonreceptive shortly after mating, sometimes within $1 \mathrm{hr}$ (Schwagmeyer and Brown, 1983). Similarly, our captive females were in vaginal estrus 24- 
TABLE 1

Female-Male Pairings in Thirteen-Lined

Ground Squirrels

\begin{tabular}{lcc}
\hline & \multicolumn{2}{c}{ Number of females } \\
\cline { 2 - 3 } & Pregnant & Not pregnant \\
\hline $1985^{4}$ & & \\
Nor-Imm & 8 & 0 \\
Nor-Dly & 0 & 4 \\
& $1986^{b}$ & 3 \\
Nor-Imm & 2 & 5 \\
Nor-Dly & 1 & 1 \\
Dly-Imm & 5 & \\
\hline
\end{tabular}

Note. Group names refer to (1) the time of removal from the coldroom; Nor (Normal) or Dly (Delayed $=10$ days) and (2) the interval between removal from the coldroom and pairing with a male: Imm (Immediate) or Dly (Delayed); Imm $=4$ days after removal from the coldroom, Delay $=22$ days in 1985 and 14 days in 1986.

${ }^{a} \chi^{2}$ significant at $P \leqslant 0.001$

${ }^{b} 3 \times 2 \chi^{2}$ significant at $P \leqslant 0.001$. Nor-Dly $\times$ Dly-Imm Fisher's test significant at $\boldsymbol{P} \leqslant \mathbf{0 . 0 0 1}$.

$48 \mathrm{hr}$ after coldroom removal (with removal coincident with the approximate emergence dates of free-living females). Females were behaviorally receptive at this time since those paired with males typically mated within the next $48 \mathrm{hr}$. Vaginal estrus terminated within 7-8 days of mating, with behavioral receptivity probably ending sooner. Pregnant females remained in a relatively constant state of diestrus at least until parturition, consistent with other rodents (e.g., Goldfoot and Goy, 1970). In the absence of mating, bchavioral receptivity terminated within 2 weeks of coldroom removal, though vaginal estrus continued for several more weeks before decreasing in frequency (see also Foster (1934) on S. tridecemlineatus, Holmes and Landau (1986) on $S$. beldingi, and Michener (1980) on $S$. richardsonii). These results suggested a link between vaginal and behavioral estrus, but one limited to near the time of removal from the cold (see also Sawrey and Dewsbury (1985) and Milligan (1982)).

Laboratory matings allowed us to investigate the duration of the postemergence period when female $S$. tridecemlineatus were reproductively active. Little has been published on the timing and control of femalemating activity in thirteen-lined ground squirrels (or any other spermophile), in part because attempts to breed these animals in captivity were unsuccessful, despite intensive efforts (Johnson and Wade, 1931; Bridgwater, 1966; Barr and Musacchia, 1968). Thus, our success in mating pairs in 
a standard laboratory environment is an important step toward describing and explaining reproductive timing in female ground squirrels.

Although vaginal estrus persisted relatively uninterrupted during the month following coldroom removal, behavioral estrus apparently did not. Thus, none of the 1985 females paired with males 22 days after coldroom removal showed evidence of mating (e.g., no pregnancies resulted nor was any sperm detected in the vaginal lavages). At this time, females remained in vaginal estrus, though their estrous condition was not as persistent as it had been earlier.

In 1986, only one of six Nor-Dly females (first paired with males 14 days after coldroom removal) showed evidence of mating (e.g., for the remaining five females: no pregnancies resulted, no sperm detected in vaginal lavages, and no matings observed on videotapes). This is striking because, at the time of pairing, these females were still clearly in their initial period of persistent estrus. Indeed, their vaginal lavages were indistinguishable from those occurring earlier in Nor-Imm females that did mate. Moreover, Dly-Imm females did mate when paired with males on the same calendar date as Nor-Dly females. What distinguished these two groups was that Nor-Dly females spent 10 days at room temperature while Dly-Imm females remained in the coldroom. Apparent failure to mate by Nor-Dly females seems to be a function of time since removal from the coldroom rather than the actual calendar date, at least within the limited time span used here. Mating by Dly-Imm females also indicates that males were still reproductively competent.

The above discussion presumes that animals that did not become pregnant also did not mate. It remains possible that an unobserved mating occurred that did not lead to pregnancy, although we think this is unlikely, based on three lines of indirect evidence. First, sperm were detected only in animals subsequently shown to be pregnant. If there were instances in which males mated with females but pregnancy did not occur, we might have recorded at least one instance of the presence of sperm in a female that did not become pegnant. This did not happen. Second, in all females that became pregnant (whether sperm were detected or not), there was a clear change in vaginal estrus (see below). This vaginal shift never occurred in a nonpregnant female. If one expected mating activity (independent of the occurence of pregnancy) to induce changes in vaginal estrus in this species, then the evidence again suggests that no mating occurred in females that did not become pregnant. Third, there was no instance of mating behavior observed on a videotape involving a female who did not become pregnant.

Finally, it is possible that the females were behaviorally receptive but that mating did not occur due to a decline in male reproductive activity. However, we think this is also unlikely. Males' testes remained descended in darkly pigmented scrota, signs of reproductive status, and histological 
studies of testes and accessory glands by Wells (1935) suggest that gonadal regression should not have begun until several weeks after pairings were completed. Also, some of the same males that impregnated Dly-Imm and Nor-Imm females were placed with Nor-Dly females, but without a resulting pregnancy.

While captive females terminated vaginal estrus within a week of mating, remaining in diestrus throughout gestation, unmated females persisted in vaginal estrus throughout most of this same period (i.e., 3-5 weeks). These findings suggest both that mating activity apparently changed endocrine secretions, which affected vaginal cytology, and mating activity probably induced ovulation. Dripps (1919) reasoned that ovulation was induced in thirteen-lined ground squirrels because corpora lutea were not detectable during histological examinations of unmated females. In the absence of direct histologic or endocrine data, we cannot be certain that ovulation is induced by mating, although circumstantial evidence supports this likelihood.

In 1984, the initial uninterrupted estrous period was briefer for Yearlings than for Adults. This pattern repeated itself in 1985 when the former Yearlings were 2-Year-Olds, which suggests that age alone does not explain the difference. Both prior reproductive experience and whether the animals had been born in the laboratory may have been relevant. A 3-week delay in removal from the coldroom also resulted in a briefer initial estrous period, but these females were otherwise similar to females removed at the "normal" time. These differences are similar to those reported in a parallel study on Belding's ground squirrels (Holmes and Landau, 1986).

Annual cycles of activity and inactivity that characterize most North American ground squirrels represent circannual rhythms (Davis, 1976; Michener, 1984). Although these cycles are generated endogenously, they are also sensitive to environmental variables (e.g., snowmelt, ambient tempcraturc) and bchavioral events (c.g., emergence) whose timing varics annually (Kenagy, 1986). Spring temperatures may be particularly critical for the seasonal synchronization of circannual cycles in ground squirrels (Joy and Mrosovsky, 1985). Our results (Table 1) suggest that, following removal from the cold, there is a limited "window" during which females are sexually receptive. We have not yet studied a wide range of "emergence" dates, but our current results reveal that when captive females are removed from the cold coincident with emergence of free-living animals a receptive period begins that terminates within a few weeks. It may be that an endogenous circannual mechanism provides first-order control to time annual reproductive activities (Zucker and Licht, 1983) and that emergence from hibernation acts as a second-order control to time behavioral receptivity (discussion in Kenagy, 1986).

Functionally, the timing of female reproduction is important to hibernating 
ground squirrels because offspring must both grow and fatten prior to winter dormancy. Probably because of their small size (relatively high surface area to volume ratio compared with adults), about $60 \%$ of all juveniles disappear during their first winter's hibernation $(S$. lateralis, Bronson, 1979; S. richardsonii, Michener and Michener, 1977; S. columbianus, Murie and Harris, 1982; S. beldingi, Sherman and Morton, 1984; S. armatus, Slade and Balph, 1974). Females mating within a few days of emergence would maximize the time juveniles have for prehibernatory fattening. Indeed, species living at high elevations or latitudes do mate within 5 days of emergence (Table 3 in Michener, 1985). Similarly, northern populations of $S$. tridecemlineatus, whether in the field (Schwagmeyer and Brown, 1983) or in the laboratory (this study), mate within 1 week of beginning their springtime activities. In contrast, females in more southern populations, where time constraints on growth and fattening are presumably not as great, begin mating $2-4$ weeks after vernal emergence (McCarley, 1966).

Termination of receptivity within 2 weeks of coldroom removal (compare Nor-Dly and Dly-Imm females) suggests that thirteen-lined ground squirrels may possess a safeguard against pregnancies occurring too late in the season for offspring to fatten adequately prior to hibernation. This might be particularly important during years in which events (such as a spring snowstorm) delay the onset of the mating period (Morton and Sherman, 1978). Presumably, such a safeguard would not be as important in southern populations where vegetative growing seasons are longer. Consistent with this prediction, females in these populations will, if their first litter is lost during lactation, resume estrus, mate, and produce a second litter (McCarley, 1966).

\section{ACKNOWLEDGMENTS}

We thank B. Iversen, W. Stebbins, W. Woolman, B. Cargill, T. Eddy, and B. Safko for assistance in data collection. We also thank T. Lee and I. Zucker for their comments on an earlier version of this manuscript. Our work was supported by funds from the Department of Psychology and the College of Arts and Sciences at Oakland University (I.T.L.) and by funds from the Department of Psychology and a Rackham faculty research grant at the University of Michigan (W.G.H.).

\section{REFERENCES}

Armitage, K. B., Downhower, J. F., and Svendsen, G. E. (1976). Seasonal changes in weights of marmots. Amer. Midl. Nat. 96, 36-51.

Barr, R. E., and Musacchia, X. J. (1968). Breeding among captive Citellus tridecemlineatus. J. Mammal. 49, 343-344.

Bridgwater, D. D. (1966). Laboratory breeding, early growth development and behavior of Citellus tridecemlineatus (Rodentia). Southwest. Nat. 11, 325-337.

Bronson, M. T. (1979). Altitudinal variation in the life history of the golden-mantled ground squirrel (Spermophilus lateralis). Ecology 60, 272-279.

Bronson, M. T. (1980). Altitudinal variation in emergence time of golden-mantled ground squirrels (Spermophilus lateralis). J. Mammal. 61, 124-126. 
Davis, D. E. (1976). Hibernation and circannual rhythms of food consumption in marmots and ground squirrels. Q. Rev. Biol. 51, 477-513.

Dripps, D. (1919). Studies on the ovary of the spermophile (Spermophilus citellus tridecemlineatus) with special reference to the corpus luteum. Amer. J. Anat. 25, 117184.

Fadem, B. H., and Rayve, R. S. (1985). Characteristics of the oestrous cycle and influence of social factors in grey-tailed opossums (Monodelphis domestica). J. Reprod. Fert. $73,337-342$.

Foster, M. A. (1934). The reproductive cycle in the female ground squirrel, Citellus tridecemlineatus (Mitchell). Amer. J. Anat. 54, 487-511.

Goldfoot, D. A., and Goy, R. W. (1970). Abbreviation of behavioral estrus by coital and vaginocervical stimulation. J. Comp. Physiol. Psychol. 72, 426-434.

Hall, E. R. (1981). The Mammals of North America, Vol. 1, 2nd ed., pp. 381-415. Wiley, New York.

Holmes, W. G., and Landau, I. T. (1986). Vaginal estrus in unmated Belding's ground squirrels Horm. Behav. 20, 243-248.

Johnson, G. E., and Wade, N. J. (1931). Laboratory reproduction studies on the ground squirrel, Citellus tridecemlineatus pallidus, Allen. Biol. Bull. 61, 101-114.

Joy, J. E. (1984). Population differences in circannual cycles of thirteen-lined ground squirrels. In J. O. Murie and G. R. Michener (Eds.), The Biology of Ground-Dwelling Squirrels, pp. 125-141. Univ. of Nebraska Press, Lincoln.

Joy, J. E., and Mrosovsky, N. (1985). Synchronization of circannual cycles: A cold spring delays the cycles of thirteen-lined ground squirrels. J. Comp. Physiol. A. 156, 125134.

Kenagy, G. J. (1986). Strategies and mechanisms for timing of reproduction and hibernation. In H. C. Heller, X. J. Musacchia, and L. C. H. Wang (Eds.), Living in the Cold: Physiological and Biochemical Adaptations, pp. 383-392. Elsevier, New York.

Knoph, F. L., and Balphs, D. F. (1977). Annual periodicity of Uinta ground squirrels. Southwest. Nat. 22, 213-224.

McCarley, H. (1966). Annual cycle, population dynamics and adaptive behavior of Citellus tridecemlineatus. J, Mammal. 47, 294-316.

Michener, G. R. (1979). The circannual cycles of Richardson's ground squirrels in southern Alberta. J. Mammal. 60, 760-768.

Michener, G. K. (1980). Estrous and gestation periods in Richardson's ground squirrels. J. Mammal. 61, 531-534.

Michener, G. R. (1984). Age, sex and species differences in the annual cycles of grounddwelling sciurids: Implications for sociality. In J. O. Murie and G. R. Michener (Eds.), The Biology of Ground-Dwelling Squirrels, pp. 81-107. Univ. of Nebraska Press, Lincoln.

Michener, G. R. (1985). Chronology of reproductive events for female Richardson's ground squirrels. J. Mammal. 66, 280-288.

Michener, G. R., and Michener, D. R. (1977). Population structure and dispersal in Richardson's ground squirrels. Ecology 58, 359-368.

Milligan, S. R. (1982). Induced ovulation in mammals. Oxford Rev. Reprod. Biol. 4, 146.

Moore, C. R., Simmons, G. F., Wells, L. J., Zalesky, M., and Nelson, W. O. (1934). On the control of reproductive activity in an annual-breeding mammal (Citellus tridecemlineatus). Anat. Rec. 60, 279-289.

Morton, M. L., and Sherman, P. W. (1978). Effects of a spring snowstorm on behavior, reproduction, and survival of Belding's ground squirrels. Canad. J. Zool. 12, 25782590. 
Murie, J. O., and Harris, M. A. (1982). Annual variation of spring emergence and breeding in Columbian ground squirrels (Spermophilus columbianus). J. Mammal. 63, 431-439.

Murie, J. O., and Michener, G. R. (1984). The Biology of Ground-Dwelling Squirrels. Univ. of Nebraska Press, Lincoln.

Sawrey, D. K., and Dewsbury, D. A. (1985). Control of ovulation, vaginal estrus, and behavioral receptivity in voles (Microtus). Neurosci. Biobehav. Rev. 9, 563-571.

Schwagmeyer, P. L. (1979). The function of alarm calling behavior in Spermophilus tridecemlineatus, the thirteen-lined ground squirrel. Ph.D. thesis, University of Michigan, Ann Arbor.

Schwagmeyer, P. L. (1984). Multiple mating and intersexual selection in thirteen-lined ground squirrels. In J. O. Murie and G. R. Michener (Eds.), The Biology of GroundDwelling Squirrels, pp. 275-293. Univ. of Nebraska Press, Lincoln.

Schwagmeyer, P. L., and Brown, C. H. (1983). Factors affecting male-male competition in thirteen-lined ground squirrels. Behav. Ecol. Sociobiol. 13, 1-6.

Sherman, P. W., and Morton, M. L. (1984). Demography of Belding's ground squirrels. Ecology 65, 1617-1628.

Slade, N. A., and Balph, D. F. (1974). Population ecology of Uinta ground squirrels. Ecology 55, 989-1003.

Turner, C. D., ,and Bagnara, J. I. (1976). General Endocrinology, 6th ed. Saunders, Philadelphia.

Wells, L. J. (1935). Seasonal sexual rhythm and its experimental modification in the male of the thirteen-lined ground squirrel (Citellus tridecemlineatus). Anat. Rec. 62, 409447.

Zucker, I., and Licht, P. (1983). Circannual and seasonal variations in plasma luteinizing hormone levels of ovariectomized ground squirrels (Spermophilus lateralis). Biol. Reprod. 28, 178-185. 